\title{
LA CARACTERIZACIÓN DE LA JUVENTUD PERONISTA EN EL DISCURSO DE CRISTINA FERNÁNDEZ DE KIRCHNER
}

(The characterization of peronist youth in the speech of Cristina Fernández de Kirchner)

Rocío Flax ${ }^{1}$

(Universidad de Buenos Aires)

\begin{abstract}
This article analyzes the social representations of the the militant youth made by Argentina's president in her speech delivered on September 14 $4^{\text {th }}, 2010$, at the Luna Park stadium. The aim is to show how Cristina Fernández positioned her direct recipients, the Peronist Youth, from a tension between inclusion and exclusion in the same collective identification. Although many fans are part of the same group, the Peronist, she cannot avoid the differences: they belong to different generations. The comparison between the so-called "Wonderful Youth", in which Fernandez is included, and the current "Youth of the Bicentennial", allow the President to place herself in a higher function within a shared community, creating a bond based upon her mandate. The research is grounded on the framework of Critical Discourse Analysis and uses the methodological tools of Systemic Functional Linguistics.
\end{abstract}

Keywords: Critical Discourse Analysis, political discourse, social representations, identity construction, Peronism.

\section{RESUMO}

Neste artigo, analisamos as representações sociais em torno à juventude militante que constrói a presidenta argentina em seu discurso, proferido em 14 de setembro de 2010 no estádio Luna Park. Buscar-se-á mostrar como Cristina Fernández situa seus destinatários diretos, a Juventude Peronista, a partir de uma tensão entre a inclusão e a exclusão em um mesmo coletivo de identificação. Embora muitos adeptos façam parte de um mesmo grupo, o do Peronismo, ela não pode evitar as diferenças: pertencem a distintas gerações. A comparação entre a denominada "Juventude Maravilhosa", na que Fernández se inclui, e a atual "Juventude do Bicentenário" permite à Presidenta colocar-se na função maior dentro de uma comunidade compartilhada e gerar um vínculo baseado no seu mandato. A pesquisa inscreve-se dentro do quadro da Análise Crítica do Discurso e utiliza as ferramentas metodológicas da Linguística Sistêmico-Funcional.

Palavras claves: Análise Crítica do Discurso; discurso político; representações sociais, construção de identidade; Peronismo.

\section{Introducción}

Si bien la agrupación política argentina denominada La Cámpora comenzó a gestarse con la llegada del kirchnerismo al poder, recién a principios del 2010 - más precisamente el 11 de marzo - en el acto en homenaje a la victoria electoral de Héctor Cámpora en 1973, la juventud kirchnerista comienza a cobrar importancia en la escena pública. Sin embargo, ni en esta oportunidad ni tampoco en el siguiente acto organizado por distintas fracciones de la

\footnotetext{
${ }^{1}$ Becaria doctoral del Consejo Nacional de Investigaciones Científicas y Técnicas de Argentina. Licenciada en Letras con orientación en Lingǘstica por la Universidad de Buenos Aires. Se desempeña como docente e investigadora de dicha institución. Áreas de interés: Sociolingüística, Análisis del Discurso. 
Juventud Peronista kirchnerista, el 14 de septiembre de 2010, el nombre de La Cámpora sobresalió especialmente. La irrupción masiva de este movimiento en la escena pública coincidió con el día de la muerte de Néstor Kirchner. Los jóvenes, en general, tuvieron una representatividad muy considerable en el velorio del ex presidente, pero los medios masivos de comunicación -tanto los gráficos como los audiovisuales- recalcaron el particular entusiasmo de un sector de la juventud kirchnerista: La Cámpora.

Desde una perspectiva lingüístico-discursiva, buscamos comprender la especificidad de la construcción, desarrollo y eventual afianzamiento de una agrupación política, tomando el caso de La Cámpora (integrada a la Juventud Peronista) y su posición dentro del escenario político argentino actual. En este trabajo, nos proponemos analizar las representaciones sociales entorno a la juventud militante que construye la Presidenta Cristina Fernández de Kirchner en su discurso del 14 de septiembre de 2010 en un acto en el Estadio Luna Park, organizado por la Juventud Peronista. Tomamos como ejes de análisis la utilización de tres vocativos referidos a la juventud militante: 1) "compañeros", 2) “chicos" y 3) "hermano". Todos se refieren al público del acto, constituido en su mayoría por diferentes corrientes de la Juventud Peronista y, por lo tanto, consideramos que suponen formas diferentes no solo de nombrar, sino de caracterizar a los mismos actores sociales. En el primero, se busca la inclusión de los jóvenes y Cristina Fernández dentro de un mismo grupo, donde predominan las relaciones de igualdad. En el segundo, existe una asimetría que se construye desde el lugar del poder, pero en un sentido generacional, activando las representaciones vinculadas con el legado y la herencia, que dentro del interdiscurso peronista se relacionan con el "trasvasamiento generacional" que planteaba el General Juan Domingo Perón a principio de la década del '70. Por último, veremos que el tercer caso posee una función históricamente más compleja que combina los lazos sociales solidarios con los lazos de parentesco pero, a diferencia del caso anterior, a partir de la horizontalidad.

El trabajo tiene el siguiente ordenamiento: en primer lugar, presentamos el marco teórico y la metodología; en los dos apartados siguientes, realizamos un análisis del discurso de Cristina Fernández a partir de los ejes propuestos; por último, presentamos algunas conclusiones que se pueden obtener a partir de los resultados del presente trabajo, en relación con otros trabajos sobre la misma temática (FLAX, 2013, 2014).

\section{Marco teórico}


El Análisis Crítico del Discurso (ACD) parte de la consideración de una interdependencia reciproca entre prácticas sociales y prácticas discursivas (FAIRCLOUGH, 2005: 79). Para esta corriente, el análisis debe comenzar por las prácticas sociales para observar el funcionamiento de los discursos vinculados con esas áreas de la actividad social y el papel que juegan en la producción y reproducción del poder. Hay que tener en cuenta que los discursos no envuelven solamente un campo de objetos sino también la definición de una perspectiva legitima para el agente de conocimiento en un determinado contexto (van LEEUWEN, 2008). Es decir que no solo representan lo que sucede sino que lo evalúan, le adscriben propósitos, lo legitiman o deslegitiman.

Esta línea teórica (FAIRCLOUGH, 2003, 2005) considera que todo fenómeno discursivo posee tres dimensiones interrelacionadas: constituye una práctica social, una práctica discursiva y una práctica textual. Es importante resaltar que el punto de partida no son las prácticas discursivas, sino las prácticas sociales, entre las cuales están incluidos los discursos. Sin embargo, el análisis lingüístico concreto comienza por la práctica textual, entendida como su materialidad lingüística.

\section{Metodología}

Para el análisis de la práctica textual, se utilizan las herramientas metodológicas propuestas por la Lingüística Sistémico-Funcional (HALLIDAY, 1982) que considera al lenguaje como un potencial de significado que se realiza gramaticalmente a través de las opciones disponibles dentro del sistema de la lengua. Por lo tanto, la utilización por parte del hablante/escritor de ciertas opciones léxico-gramaticales permite dar cuenta de los significados que puso en juego, los que se vinculan directamente con el registro -las opciones elegidas tomando en cuenta el contexto de producción-, con el género -las opciones elegidas según el contexto cultural más amplio- y, en última instancia, con la ideología que se encuentra en el texto.

El registro está compuesto por tres elementos -campo, tenor y modo- que, a su vez, se realizan a través de las tres metafunciones básicas del lenguaje: la función ideacional da cuenta de las representaciones que el hablante/escritor tiene del mundo y de él mismo; la función interpersonal expresa los roles que asume el hablante/escritor y los que le impone a los demás; y la función textual incluye los recursos para que un hablante/escritor pueda formar un texto coherente. En este trabajo se analizan las dos primeras metafunciones. 
Para el análisis de la metafunción ideacional se indaga el sistema de transactividad propuesto por la Lingüística Crítica - reformulación del sistema de transitividad de la Lingüística Sistémico-Funcional - (HODGE \& KRESS, 1979). Este modelo clasifica los términos de un texto -en cada cláusula- en categorías de procesos y de participantes, para luego dar cuenta de la distribución de los participantes según posean o no agentividdad y según los procesos a los que son asociados.

Así, la cláusula típica está formada por dos participantes vinculados entre sí por un proceso, que contiene la marca temporal. Estas cláusulas, denominadas transactivas, se caracterizan porque uno de sus participantes posee el rol de agente (de un proceso material, de reacción o semiótico) y un participante afectado. Las cláusulas no transactivas son aquellas que poseen un solo participante - agente o afectado - asociado a un proceso. Por último, se postula un tercer tipo de cláusula, llamada relacional, que establece una relación entre una entidad relacionante y otro elemento: las relacionales ecuativas sirven para establecer una identificación entre ambos elementos; las relacionales atributivas y posesivas le adscriben características a la identidad relacionante; y las locativas vinculan a la entidad con sus circunstancias espaciales.

Con respecto a la función interpersonal, resulta relevante para este trabajo considerar que, en un primer momento, la Lingüística Sistémico-Funcional consideraba dos elementos que influían en las elecciones del hablante: las diferencias de poder y la frecuencia del contacto. Reformulaciones posteriores (POYNTON, 1990; MARTIN, 1992; WHITE, 2004) proponen considerar, además, el nivel afectivo y la solidaridad tanto valorativa como ideológica.

Para el análisis de la metafunción interpersonal se analiza el sistema de modo (HALLIDAY, 1982) que tiene en cuenta la modalidad de la cláusula, el sujeto gramatical, el elemento finito (compuesto por la flexión verbal y la polaridad, ya sea positiva o negativa) y los adjuntos modales que representan matices deónticos, volitivos, epistémicos, etc.

\section{EI discurso}

Este discurso ${ }^{2}$ fue pronunciado por la Presidenta argentina Cristina Fernández en el marco de un acto organizado por diferentes corrientes de la Juventud Peronista, una de las

\footnotetext{
${ }^{2}$ Este discurso fue recogido de la página del poder ejecutivo argentino www.casarosada.gov.ar y chequeado con su versión en video.
} 
cuatro ramas históricas del Movimiento Peronista. El orador principal debía ser Néstor Kirchner, pero por un problema coronario le cedió el puesto a su esposa.

Si consideramos primero la estructura del discurso según los temas que aborda, vemos que luego de una breve introducción Cristina Fernández expresa: "Verlos a ustedes. Verlos a ustedes me hace recordar parte de la historia de mi propia vida y también la de nuestro país" (cláusulas 15-18). Este enunciado le permite realizar una comparación entre las condiciones de la juventud actual y la de su generación (cláusulas 12- 43). Luego, pasa a realizar un recorrido histórico que - haciendo hincapié en el periodo 1973-1976 - abarca desde los primeros gobiernos de Perón hasta el gobierno Kirchnerista (cláusulas 44-153). Junto con el relato histórico, aparecen otros dos tipos de enunciados: 1) los evaluativos y 2) aquellos que poseen una modalidad deóntica. Estos últimos les indican a sus destinatarios qué es correcto hacer.

Tradicionalmente, en todas las sociedades, tanto orientales como occidentales, el mayor es fuente de experiencia y sabiduría (MEAD 1928, 1970). Es por esto que la edad es considerada como uno de los factores que determinan las asimetrías en la dimensión interpersonal del poder (POYNTON, 1990; MARTIN \& WHITE, 2005). En este sentido, la utilización de evaluativos y deónticos no se justifica sólo por el rol de líder de la Presidenta, sino por el público al cual le habla: diferentes facciones de la Juventud Peronista. Así, Fernández se encuentra autorizada para mostrar cuál es el camino correcto a seguir y qué es lo que los jóvenes deben hacer. Efectivamente, a lo largo de todo el discurso, algunos de los enunciados que poseen modalidad deóntica constituyen, no ya directrices generales para el movimiento kirchnerista, sino órdenes sobre las acciones concretas que la juventud tiene que realizar. Estos enunciados están construidos ya sea a través de la modalidad deóntica explicita (“deben", "tienen que"), a través de imperativos, u otras formas de marcar ordenes, como los infinitivos (“¡a levantar esa consigna fuerte, a levantar esa consigna fuerte!” 440-441 ${ }^{3}$ ).

Luego del recorrido histórico, el discurso se vuelve hacia el presente para evaluar la situación actual (165-444). Esto sirve de excusa para recordar las medidas más populares tomadas por el gobierno como la Ley de Medios Audiovisuales, la Asignación Universal por Hijo, la estatización de los fondos jubilatorios privados, etc. También sirve para volver a marcar el deber ser, ahora a través de las cosas que falta realizar. Al indicar lo que falta hacer, vuelve a introducir fragmentos deónticos dirigidos a los jóvenes, que señalan la forma en que

\footnotetext{
${ }^{3}$ Los números entre paréntesis que aparecen a lo largo del trabajo corresponden al número de cláusulas. Realizamos la segmentación de acuerdo a la definición de cláusula de Halliday (1982). 
ellos deben actuar dentro del modelo político propuesto. Aquí se hace referencia a la oposición, cuya especificidad es puramente negativa: poner obstáculos a las medidas del gobierno y atacar al oficialismo (representados como el único colectivo comprometido con la mejora del país).

Más adelante, hay una convocatoria explícita a la juventud. A partir de la cláusula 445, hay una transición que une los dos temas anteriores (pasado y presente argentino) con el rol de la juventud. Una vez más nos encontramos con la modalidad deóntica, esta vez construida a partir de una estructura condicional:

pero cuando uno tiene la oportunidad de poder estudiar, cuando uno tiene la oportunidad de poder acceder a una universidad pública nacional y gratuita, cuando uno tiene la posibilidad de expresarse con libertad, tiene también la obligación de comprometerse profundamente con la patria y con los que menos tienen, a los que todavía hay que llegar (452-461).

Ese uso impersonal del uno (LAVANDERA, 1984, 1985) que, al generalizar la referencia, mitiga la orden por no especificar quiénes deben comportarse de la forma prescripta, se carga de sentido en la cláusula siguiente, a través del llamado a los jóvenes a organizarse:

Yo los convoco. Yo los convoco a los jóvenes de los movimientos sociales,
de las organizaciones sindicales, de las juventudes universitarias, de las
juventudes territoriales, a todos, a transformarse en un multitudinario
colectivo que recorra el país, que vaya ahí donde se necesita una mano, una
ayuda solidaria. Es el mejor testimonio que podemos dar de nuestro
compromiso con el prójimo y con la historia, eso fue humildemente lo que
intentamos hacer cuando éramos mucho más jóvenes. Hoy, hoy esta
maravillosa movilización no es casualidad, lo dijo el Cuervo, no, es para
ustedes, yo ya fui, hermano, es para ustedes, ustedes son el futuro hermano,
ustedes tienen que agarrar las banderas y llevarlas adelante, ponerse para
saber que cada lugar que no ocupa el compañero que tiene objetivos, que
cada lugar donde no está la compañera que quiere tender la mano solidaria al
otro, es posible que lo ocupe alguno que solamente le importa su destino
personal (462-488).

Una vez más, vuelve a dirigirse a la juventud para marcar lo que deben hacer, a través del infinitivo, el modo subjuntivo y la modalidad deóntica. Estas directivas son los elementos predominantes del fragmento. Al igual que en la sección anterior, se intercalan medidas tomadas por el gobierno, en este caso a favor de la juventud, como las becas universitarias del Bicentenario. Aquí también hay una amplia utilización de la modalidad volitiva (a través del 
uso del subjuntivo), que marca lo que Fernández espera ver en el futuro. Por supuesto, es otra forma de marcar lo que quiere que la juventud haga:

Yo voy a ser. Yo voy a ser definitivamente feliz el día que pueda volver a ver a millones de jóvenes con sus banderas desplegadas, con sus cánticos, sin violencia (509-511).

Cuando vea millones de jóvenes que estudian, que trabajan, pero al mismo tiempo se comprometen y eligen un objetivo de vida (522-526).

\section{La construcción de la Juventud Peronista del Bicentenario}

Juventud Peronista del Bicentenario: así es como Fernández denomina a los jóvenes militantes en su discurso, en un gesto fundacional y constitutivo. Ya no son la variedad de agrupaciones diferenciadas que convocaron al acto, sino que forman parte de un todo que los une y les otorga una identidad generacional. "Frente a ustedes, a la que denomino, a la que denomino "Juventud Peronista del Bicentenario"' (44-45). Este colectivo es su destinatario directo, son los que organizaron y asistieron al acto. El resto de los ciudadanos puede acceder al discurso a través de los medios de comunicación en forma parcial o total. Sin embargo, hay fragmentos donde parecería dirigirse a su partido político en general, a la clase media y a los argentinos:

Y cuando hablo de nosotros aquí, hablo de los argentinos (91-92).

Pero como cuadros políticos, tenemos la obligación de analizar la historia en su exacta dimensión (141-142).

A nosotros, a nosotros, a nosotros cuando alguien nos pregunta algo nos interrogan, a ellos los escuchan, pero no importa, esto nos hace muy bien porque nos hace ejercitarnos como cuadros en la dialéctica y en la discusión (253-259).

Y acá les quiero hablar a nosotros mismos, a esta clase media tan volátil, a esta clase media como yo, universitaria, a esta clase media (159).

No obstante, estos supuestos destinatarios diferenciados constituyen formas de ir caracterizando a la juventud militante, ya que son ellos los destinatarios directos del mensaje y a quienes corresponde identificar como parte del nosotros inclusivo. En efecto, forman parte del colectivo de los argentinos, pero también son cuadros dentro de un partido. En la última cita, la locutora del discurso se identifica con sus destinatarios por formar parte de la clase media y, además, universitaria. Esto se encuentra en consonancia con otro fragmento del discurso donde queda claro que la juventud peronista que está presente en el acto no 
corresponde al sector sindical": "si nosotros hubiéramos podido sentarnos junto a los jóvenes de la Juventud Sindical, como ustedes se sientan ahora" (41-42).

Consideremos los siguientes enunciados:

Otra cosa que tampoco muchas veces se ha entendido en la República Argentina es que no solamente nos hemos equivocado los jóvenes o la clase media (583-584).

Por eso digo que los envidio mucho pero esto también les crea muchas responsabilidades, nosotros tuvimos que abrirnos como podíamos, a los codazos, o como podíamos porque no había libertades, pero cuando uno tiene la oportunidad de poder estudiar, cuando uno tiene la oportunidad de poder acceder a una universidad pública nacional y gratuita... (445-460).

En el primer fragmento el nosotros que une a la locutora con sus destinatarios está caracterizado como joven (ahora o en los '70) o como de clase media. En el segundo, la diferencia entre nosotros/uno es generacional. Gramaticalmente se realiza a través de la oposición pretérito perfecto simple y pretérito imperfecto del indicativo referido al nosotros, y presente del indicativo referido a uno. El nosotros está constituido por la Juventud Peronista de los '70 y el uno se carga de sentido a través del ustedes que aparece implicado en "los envidio mucho". Cristina Fernández se postula como referente de la generación del '70 ("Yo formé parte de la juventud maravillosa, de esa juventud que no tuvo la oportunidad" 76-77) que viene a hablar, a aconsejar a la nueva juventud. Parecería que no hubo otro grupo de jóvenes dentro del peronismo hasta la actualidad. La Presidenta explicita esa postura: luego del 76, lo únicos jóvenes que, según el discurso kirchnerista, se sumaron a la política fueron los de la Unión Cívica Radical: "Después vino el advenimiento de la democracia y también [vino] la incorporación de miles de jóvenes a otro partido y a otro movimiento que no era el nuestro" (132-134).

A pesar de esta caracterización, donde parece excluir a la juventud sindical, esta es incluida a la hora de convocar a los jóvenes a la militancia política. Recordemos el fragmento en cuestión:

Yo los convoco. Yo los convoco a los jóvenes de los movimientos sociales, de las organizaciones sindicales, de las juventudes universitarias, de las

\footnotetext{
${ }^{4}$ El Peronismo tradicionalmente constaba de cuatro ramas: la rama política, la rama femenina, la rama sindical y la juventud. Dentro de la Juventud Peronista, había un sector de militancia de base y un sector revolucionario, ambos orientados hacia la izquierda del espectro político. En cambio, el sindicalismo (incluida la Juventud Sindical) se encontraba a la derecha. En la década del '70 las pujas entre ambos sectores llegaron a situaciones sumamente violentas.
} 
juventudes territoriales, a todos, a transformarse en un multitudinario colectivo que recorra el país, que vaya ahí donde se necesita una mano, una ayuda solidaria. (462-467).

A continuación, analizaremos los fragmentos del discurso de Cristina Fernández donde aparecen las invocaciones a los asistentes al acto, es decir, a los jóvenes. Como dijimos anteriormente, los vocativos utilizados son tres: 1) compañeros (y compañeras), 2) chicos y 3 ) hermano. Según estudios referidos a las formulas de tratamiento (RIGATUSO 1992, 1994), la utilización de vocativos coincide mayormente con dos usos distintos. Por un lado, reforzando la estructura del discurso, sus apariciones suelen darse en el saludo y la despedida. Por el otro, se lo utiliza como una expresión de intensidad, por ejemplo, cuando se busca persuadir al interlocutor de aceptar alguna petición, puesto que apela a la identificación entre los interlocutores, constituyendo una estrategia de cortesía positiva (BROWN \& LEVINSON, 1987).

\subsection{Los Compañeros}

1) Gracias, muchas gracias compañeros y compañeras (6-7).

Este fragmento no permite caracterizar demasiado a los destinatarios del mensaje. Lo único que se puede decir al respecto es que se trata de un proceso ${ }^{5}$ de conducta (agradecer) que realiza Cristina Fernández (actuante) y que recae sobre los jóvenes (alcance) considerados como iguales dentro del partido político que comparten.

2) Compañeros y compañeras, quisiera, quisiera poder contarles de la mejor manera, lo que siento en este momento. Verlos a ustedes. Verlos a ustedes me hace recordar parte de la historia de mi propia vida y también la de nuestro país. Déjenme decirles. Déjenme decirles que siento una sana envidia por todos ustedes. Pero no por lo que seguramente alguno mañana va a decir 'ah claro, querría tener 20 años, por eso se hace la nena'. No, qué va. ¿Saben por qué les tengo envidia? ¿Saben por qué les tengo envidia? Porque cuando yo fui joven como ustedes, cuando junto a miles y millones de argentinos apostábamos a un país diferente, no tuvimos la suerte que tienen ustedes hoy de vivir en un país con todas las libertades (12-34).

\footnotetext{
${ }^{5}$ Para los distintos tipos de procesos y sus roles temáticos asociados ver Halliday (1982)
} 
Tabla 1: Sistema de modo

\begin{tabular}{|c|c|c|c|c|c|c|c|}
\hline & \multirow[t]{2}{*}{ Cláusula } & \multirow{2}{*}{$\begin{array}{l}\text { Sujeto } \\
\text { gramatical }\end{array}$} & \multirow[t]{2}{*}{ Modalidad } & \multicolumn{3}{|c|}{ Elemento finito } & \multirow{2}{*}{$\begin{array}{l}\text { Adjuntos } \\
\text { modales }\end{array}$} \\
\hline & & & & $+/-$ & Tpo & Modo & \\
\hline 12 & $\begin{array}{l}\text { Compañeros y compañeras, } \\
\text { quisiera }\end{array}$ & (Yo) & Decl & + & Pret & Subj & \\
\hline 13 & $\begin{array}{l}\text { quisiera poder contarles de } \\
\text { la mejor manera, }\end{array}$ & (Yo) & Decl & + & Pres & $\mathrm{X}$ & Quisiera poder \\
\hline 14 & $\begin{array}{l}\text { lo que siento en este } \\
\text { momento. }\end{array}$ & (Yo) & Decl & + & Pres & Ind & \\
\hline 15 & Verlos a ustedes & (Yo) & Decl & + & Pres & $\mathrm{X}$ & \\
\hline 16 & Verlos a ustedes & (Yo) & Decl & + & Pres & $\mathrm{X}$ & \\
\hline 17 & me hace & $\begin{array}{l}\text { (Verlos } \quad \text { a } \\
\text { ustedes) }\end{array}$ & Decl & + & Pres & Ind & \\
\hline 18 & $\begin{array}{l}\text { recordar parte de la historia } \\
\text { de mi propia vida y también } \\
\text { la de nuestro país. }\end{array}$ & (Yo) & Decl & + & Pres & $\mathrm{X}$ & \\
\hline 19 & Déjenme decirles & $\begin{array}{l}\text { (Ustedes) } \\
\text { (Yo) }\end{array}$ & $\begin{array}{l}\text { Decl } \\
\text { Decl }\end{array}$ & $\begin{array}{l}+ \\
+\end{array}$ & $\begin{array}{l}\text { Pres } \\
\text { Pres }\end{array}$ & $\begin{array}{l}\text { Imp } \\
X\end{array}$ & \\
\hline 20 & Déjenme decirles & $\begin{array}{l}\text { (Ustedes) } \\
\text { (Yo) }\end{array}$ & $\begin{array}{l}\text { Decl } \\
\text { Decl }\end{array}$ & $\begin{array}{l}+ \\
+ \\
\end{array}$ & $\begin{array}{l}\text { Pres } \\
\text { Pres } \\
\end{array}$ & $\begin{array}{l}\text { Imp } \\
\mathrm{X}\end{array}$ & \\
\hline 21 & $\begin{array}{l}\text { que siento una sana envidia } \\
\text { por todos ustedes. }\end{array}$ & (Yo) & Decl & + & Pres & Ind & \\
\hline 22 & Pero no [siento...] por & (Yo) & Decl & - & (Pres) & (Ind) & \\
\hline 23 & $\begin{array}{l}\text { lo que seguramente alguno } \\
\text { mañana va a decir }\end{array}$ & Alguno & Decl & + & Fut & Ind & \\
\hline 24 & $\begin{array}{l}\text { "ah claro, querría tener } 20 \\
\text { años, }\end{array}$ & $(\mathrm{CFK})$ & Decl & + & Pres & $\mathrm{X}$ & $\begin{array}{l}\text { Ah, claro } \\
\text { Querría }\end{array}$ \\
\hline 25 & por eso se hace la nena". & $(\mathrm{CFK})$ & Decl & + & Pres & Ind & \\
\hline 26 & No, & $\mathrm{X}$ & Decl & - & $\mathrm{X}$ & $\mathrm{X}$ & \\
\hline 27 & qué va. & $\mathrm{X}$ & Excl & + & Pres & Ind & \\
\hline 28 & $\begin{array}{l}\text { ¿Saben por qué les tengo } \\
\text { envidia? }\end{array}$ & (Yo) & Int & + & Pres & Ind & Saben \\
\hline 29 & $\begin{array}{l}\text { ¿Saben por qué les tengo } \\
\text { envidia? }\end{array}$ & (Yo) & Int & + & Pres & Ind & Saben \\
\hline 30 & $\begin{array}{l}\text { Porque cuando yo fui joven } \\
\text { como ustedes, }\end{array}$ & Yo & Decl & + & Pret & Ind & \\
\hline 31 & $\begin{array}{l}\text { cuando junto a miles y } \\
\text { millones de argentinos } \\
\begin{array}{l}\text { apostábamos a un país } \\
\text { diferente, }\end{array}\end{array}$ & (Nosotros) & Decl & + & Pret & Ind & \\
\hline 32 & no tuvimos la suerte & (Nosotros) & Decl & - & Pret & Ind & \\
\hline 33 & que tienen ustedes hoy de & Ustedes & Decl & + & Pres & Ind & \\
\hline 34 & $\begin{array}{l}\text { vivir en un país con todas } \\
\text { las libertades. }\end{array}$ & (Ustedes) & Decl & + & Pres & $X$ & \\
\hline
\end{tabular}

Como se puede observar a partir del sistema de modo, la mayor parte de los sujetos están constituidos por la primera persona del singular y se encuentran en modo indicativo, con excepción de la cláusulas 12 y 13 que expresan volición. Los casos en los que aparece el ustedes poseen distintos matices de modalidad. Así, las primeras dos apariciones están en imperativo y las dos siguientes están marcadas por la modalidad epistémica que, sumado a la forma interrogativa, supone que los jóvenes no saben y que Cristina Fernández, quien posee 
mayor conocimiento, les va a informar. En efecto, la Presidenta pregunta y luego explica. Esta explicación realiza un movimiento que aparece en otros discursos suyos (FLAX, 2014): los compara con la generación del '70, pero marcando una mejora en las condiciones históricas objetivas. Sin embargo, en este caso, no se explicita cuáles son las mejorías, salvo por una referencia muy general: "un país con todas las libertades". Luego, el ustedes aparece otras dos veces (una con indicativo y la otra con infinitivo) para oponerse a un nosotros que reitera el contrapunto generacional. ${ }^{6}$

Al homologar su propia historia con la del país, Fernández vuelve a habilitar su rol actual de dirigente de la juventud, basándose en su experiencia pasada. Los procesos que se adjudica son verbales (contar, decir) o mentales (ver, recordar), en coincidencia con la imagen que quiere construir de ella: porque vio y ve, tiene posibilitada la palabra. En resumen, a pesar del vocativo elegido en este fragmento, prima la diferencia de poder entre hablante y destinatarios, justificada por un mayor conocimiento y experiencia.

3) Y también debemos decir compañeros y compañeras, con mucho respeto y sin ánimo de armar polémica, pero que no nos vengan a dar lecciones de democracia e instituciones porque nosotros nunca subimos con ningún partido político proscrito en el país, jamás fuimos gobierno con proscripciones políticas, jamás. Cuando nos tocó perder, nos tocó perder en buena ley, compitiendo libre y democráticamente (120-129).

Tabla 2: Sistema de modo

\begin{tabular}{|c|c|c|c|c|c|c|c|}
\hline & \multirow[t]{2}{*}{ Cláusula } & \multirow[t]{2}{*}{ Sujeto } & \multirow[t]{2}{*}{ Modalidad } & \multicolumn{3}{|c|}{ Elemento finito } & \multirow{2}{*}{$\begin{array}{l}\text { Adjuntos } \\
\text { modales }\end{array}$} \\
\hline & & & & $+/-$ & Tpo & Modo & \\
\hline 120 & $\begin{array}{l}\text { Y también debemos decir } \\
\text { compañeros y compañeras, con } \\
\text { mucho respeto y sin ánimo de }\end{array}$ & (Nosotros) & Decl & + & Pres & $\mathrm{X}$ & Debemos \\
\hline 121 & armar polémica, & (Nosotros) & Decl & + & Pres & $X$ & \\
\hline 122 & $\begin{array}{l}\text { pero que no nos vengan a dar } \\
\text { lecciones de democracia e } \\
\text { instituciones }\end{array}$ & (Ellos) & Decl & - & Pres & Subj & \\
\hline 123 & $\begin{array}{l}\text { porque nosotros nunca subimos } \\
\text { con ningún partido político } \\
\text { proscrito en el país, }\end{array}$ & Nosotros & Decl & - & Pret & Ind & Nunca \\
\hline 124 & $\begin{array}{l}\text { jamás fuimos gobierno con } \\
\text { proscripciones políticas, jamás. }\end{array}$ & (Nosotros) & Decl & - & Pret & Ind & Jamás \\
\hline 125 & Cuando nos tocó & $\mathrm{X}$ & Decl & + & Pret & Ind & \\
\hline 126 & perder, & (Nosotros) & Decl & + & Pres & $\mathrm{X}$ & \\
\hline 127 & nos tocó & $\mathrm{X}$ & Decl & + & Pret & Ind & \\
\hline
\end{tabular}

\footnotetext{
${ }^{6}$ Además de las personas que representan al emisor y el destinatario (yo-nosotros-ustedes), en el fragmento aparece una ocurrencia indefinida de "alguno", quien propaga una imagen negativa de la Presidenta. Esto hace pensar, junto con el adverbio "mañana", que puede referir a los medios de comunicación que cubren el evento.
} 


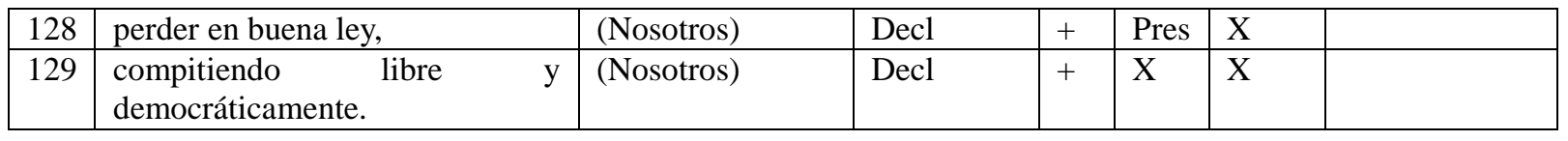

A diferencia del fragmento anterior, aquí compañeros y compañeras sí marca un vínculo de igualdad, son compañeros porque se encuentran dentro del mismo colectivo de identificación, son todos cuadros del peronismo. Esto se realiza gramaticalmente a partir del nosotros que predomina en el fragmento y que hace referencia a los peronistas. En efecto, todos los sujetos corresponden a nosotros, salvo un ellos que se refiere inespecíficamente a otros partidos políticos. Si nos remitimos al contexto histórico, vemos que, aunque no esté mencionado, solo puede referirse a los miembros de la Unión Cívica Radical (y un desprendimiento de ese partido: la Unión Cívica Radical Intransigente) que sí ganaron elecciones habiendo un partido proscripto: el Partido Justicialista (Peronismo). Al no hacer hincapié en el vínculo generacional en este ejemplo, la modalidad deóntica aparece solo una vez, predominando los procesos no modalizados en pretérito del indicativo (se relata un hecho histórico). El contrapunto con la UCR se intensifica a través del uso de los reforzadores: jamás y nunca.

4) Y nos habremos equivocado, claro que sí, pero acuérdense, no nos critican por las equivocaciones, nos critican por los aciertos, por las buenas políticas, por la equidad, por la igualdad, porque no haya más impunidad en la República Argentina, por eso nos critican compañeros, y si es por eso que sigan criticando, que sigan criticando. Tenemos espaldas para aguantar. Tenemos espaldas para aguantar, no lo hacemos porque nos creamos heroínas o demasiado fuertes, al contrario, es la voluntad inquebrantable de saber que tenemos un compromiso con nuestra propia historia y con el país, un país que ha sido demasiado castigado (397-415).

Tabla 3: Sistema de modo

\begin{tabular}{|c|c|c|c|c|c|c|c|}
\hline & Cláusula & Sujeto & Modalidad & Ele & ento 1 & & Adjuntos \\
\hline & & & & $+/-$ & Tpo & Modo & modales \\
\hline 397 & Y nos habremos equivocado, & (Nosotros) & Decl & + & Fut & Ind & \\
\hline 398 & claro que sí, & $\mathrm{X}$ & Decl & + & $\mathrm{X}$ & $\mathrm{X}$ & Claro \\
\hline 399 & pero acuérdense, & (Ustedes) & Decl & + & Pres & Imp & \\
\hline 400 & $\begin{array}{l}\text { no nos critican por las } \\
\text { equivocaciones, }\end{array}$ & (Ellos) & Decl & - & Pres & Ind & \\
\hline 401 & $\begin{array}{l}\text { nos critican por los aciertos, } \\
\text { por las buenas políticas, por } \\
\text { la equidad, por la igualdad, }\end{array}$ & (Ellos) & Decl & + & Pres & Ind & \\
\hline
\end{tabular}




\begin{tabular}{|c|c|c|c|c|c|c|c|}
\hline 402 & $\begin{array}{l}\text { porque no haya más } \\
\text { impunidad en la República } \\
\text { Argentina, }\end{array}$ & $\mathrm{X}$ & Decl & + & Pres & Subj & \\
\hline 403 & $\begin{array}{l}\text { por eso nos critican } \\
\text { compañeros, }\end{array}$ & (Ellos) & Decl & + & Pres & Ind & \\
\hline 404 & y si es por eso & (¿La crítica?) & Decl & + & Pres & Ind & \\
\hline 405 & que sigan criticando, & (Ellos) & Decl & + & $\mathrm{X}$ & $\mathrm{X}$ & Sigan \\
\hline 406 & que sigan criticando. & (Ellos) & Decl & + & $\mathrm{X}$ & $\mathrm{X}$ & Sigan \\
\hline 407 & Tenemos espaldas & (Nosotros) & Decl & + & Pres & Ind & \\
\hline 408 & para aguantar, & (Nosotros) & Decl & + & Pres & $\mathrm{X}$ & \\
\hline 409 & Tenemos espaldas & (Nosotros) & Decl & + & Pres & Ind & \\
\hline 410 & para aguantar, & (Nosotros) & Decl & + & Pres & $\mathrm{X}$ & \\
\hline 411 & no lo hacemos & (Nosotros) & Decl & - & Pres & Ind & \\
\hline 412 & $\begin{array}{l}\text { porque nos creamos heroínas } \\
\text { o demasiado fuertes, }\end{array}$ & (Nosotros) & Decl & + & Pres & Subj & \\
\hline 413 & $\begin{array}{l}\text { al contrario, es la voluntad } \\
\text { inquebrantable de }\end{array}$ & (Esto) & Decl & + & Pres & Ind & \\
\hline 414 & $\begin{array}{l}\text { saber que tenemos un } \\
\text { compromiso con nuestra } \\
\text { propia historia y con el país, } \\
\text { un país }\end{array}$ & (Nosotros) & Decl & + & Pres & Ind & Saber \\
\hline 415 & $\begin{array}{l}\text { que ha sido demasiado } \\
\text { castigado. }\end{array}$ & (Un país) & Decl & + & Pret & Ind & \\
\hline
\end{tabular}

En este ejemplo, al igual que en el anterior, los compañeros forman parte, junto con Cristina Fernández, de una agrupación política y son ellos, en su conjunto, los que son criticados y los que tienen la voluntad inquebrantable de soportar esas críticas. Aquí, los sujetos varían entre nosotros y ellos, y solo aparece un ustedes que interpela a los destinatarios a recordar (Fernández, en cambio, ya recuerda), pero que no los excluye del colectivo de identificación. A diferencia del fragmento anterior, aquí predomina el presente. Si recordamos la estructura del discurso, la parte histórica dejó paso a la enumeración de los logros del gobierno y los ataques de la oposición.

En general, en este discurso, los sujetos gramaticales coinciden con el agente que realiza las acciones o la entidad relacional (sujeto lógico). Así, en este ejemplo, los participantes activos son nosotros y ellos. Sin embargo, ellos se encuentra asociado con procesos verbales como "criticar", mientras que nosotros con procesos de reacción (que suponen un nivel de agencia voluntaria y consciente menor) como "aguantar". El nosotros también aparece asociado a procesos relacionales posesivos (tener) y mentales (creer, acordarse). El único proceso al que Fernández le borra el participante activo es al que debería indicar al agente responsable de castigar al país, dejando la responsabilidad vacia. ${ }^{7}$ Cabe

\footnotetext{
${ }^{7}$ Otra lectura posible de este fragmento es que el nosotros excluya al destinatario, refiriéndose sólo al gobierno. De cualquier forma, no aparece una oposición entre nosotros/ustedes y los asistentes al acto formarían parte del mismo colectivo de identificación -el kirchnerismo-, a diferencia del ellos. Al formar parte del mismo proyecto, 70
} 
destacar la aparición de la palabra "heroínas" en femenino, ya que si bien remite al nosotros, parece casi un corrimiento hacia un yo que representa a Cristina Fernández.

\subsection{Los chicos}

1) Bájenlas chicos, bájenlas. Sean buenos. dale (8-11).

Aquí, volvemos al modo imperativo y subjuntivo. La orden y el deseo de que esa orden sea obedecida. Se puede observar un cambio en el registro: la orden sumada al "sean buenos" establece un vinculo asimétrico pero cercano, de afecto, casi maternal con los destinatarios del mensaje, muy alejado del registro político.

2) Surge inevitable, chicos. Surge inevitable -porque estamos hablando aquí y vengo a hablar también como testigo de época-, surge inevitable comparar cuando uno le habla a la juventud de hoy de la Argentina de hoy, de esta Argentina de hoy, surge inevitable repasar y repensar qué es lo que hicimos en estos años. Yo formé parte de la juventud maravillosa, de esa juventud que no tuvo la oportunidad que hoy tenemos aquí, de esa juventud que fue masacrada durante la dictadura más terrible de la que se tenga memoria, y si se me permite, la dictadura que vino a terminar, realmente, con el modelo industrial y de generación de trabajo (64-83).

Tabla 4: Sistema de modo

\begin{tabular}{|c|c|c|c|c|c|c|c|}
\hline & \multirow[t]{2}{*}{ Cláusula } & \multirow[t]{2}{*}{ Sujeto } & \multirow[t]{2}{*}{ Modalidad } & \multicolumn{3}{|c|}{ Elemento finito } & \multirow{2}{*}{$\begin{array}{l}\text { Adjuntos } \\
\text { modales }\end{array}$} \\
\hline & & & & $+/-$ & Tpo & Modo & \\
\hline 64 & surge inevitable, chicos & (Comparar) & Decl & + & Pres & Ind & \\
\hline 65 & surge inevitable & (Comparar) & Decl & + & Pres & Ind & \\
\hline 66 & $\begin{array}{l}\text {-porque estamos hablando } \\
\text { aquí }\end{array}$ & (Nosotros) & Decl & + & Pres & Ind & \\
\hline 67 & $\begin{array}{l}\text { y vengo a hablar también } \\
\text { como testigo de época-, }\end{array}$ & (Yo) & Decl & + & Pres & Ind & \\
\hline 68 & surge inevitable & (Comparar) & Decl & + & Pres & Ind & \\
\hline 69 & comparar & (Yo) & Decl & + & Pres & $\mathrm{X}$ & \\
\hline 70 & $\begin{array}{l}\text { cuando uno le habla a la } \\
\text { juventud de hoy de la } \\
\text { Argentina de hoy, de esta } \\
\text { Argentina de hoy, }\end{array}$ & Uno & Decl & + & Pres & Ind & \\
\hline 71 & surge inevitable & $\begin{array}{ll}\text { (Repasar } & y \\
\text { repensar) } & \end{array}$ & Decl & + & Pres & Ind & \\
\hline 72 & repasar & (Yo) & Decl & + & Pres & $\mathrm{X}$ & \\
\hline
\end{tabular}

y ser la intención del discurso profundizar el compromiso de los militantes, las acciones se le pueden atribuir al peronismo kirchnerista en su totalidad y no solo a los miembros del gobierno. 


\begin{tabular}{|c|c|c|c|c|c|c|}
\hline 73 & y repensar & (Yo) & Decl & + & Pres & $\mathrm{X}$ \\
\hline 74 & qué es & (Lo que...) & Decl & + & Pres & Ind \\
\hline 75 & $\begin{array}{l}\text { lo que hicimos en estos } \\
\text { años. }\end{array}$ & (Nosotros) & Decl & + & Pret & Ind \\
\hline 76 & $\begin{array}{l}\text { Yo formé parte de la } \\
\text { juventud maravillosa, de } \\
\text { esa juventud }\end{array}$ & Yo & Decl & + & Pret & Ind \\
\hline 77 & que no tuvo la oportunidad & $\begin{array}{l}\text { (La juventud } \\
\text { maravillosa) }\end{array}$ & Decl & - & Pret & Ind \\
\hline 78 & que hoy tenemos aquí, & (Nosotros) & Decl & + & Pres & Ind \\
\hline 79 & $\begin{array}{l}\text { [formé parte] de esa } \\
\text { juventud }\end{array}$ & (Yo) & Decl & + & (Pret) & (Ind) \\
\hline 80 & $\begin{array}{l}\text { que fue masacrada durante } \\
\text { la dictadura más terrible de }\end{array}$ & Esa juventud & Decl & + & Pret & Ind \\
\hline 81 & la que se tenga memoria, & $\mathrm{X}$ & Decl & + & Pres & Subj \\
\hline 82 & y si se me permite, & $\mathrm{X}$ & Decl & + & Pres & Ind \\
\hline 83 & $\begin{array}{l}\text { la dictadura que vino a } \\
\text { terminar, realmente, con el } \\
\text { modelo industrial y de } \\
\text { generación de trabajo. }\end{array}$ & $\begin{array}{l}\text { (La } \\
\text { dictadura) }\end{array}$ & Decl & + & Pres & Ind \\
\hline
\end{tabular}

Aquí, chicos se refuerza con el sintagma "testigo de época" que marca la diferencia generacional entre ambos, hablante y destinatarios. El contrapunto también está presente en "uno que le habla a la juventud", siendo ese uno la propia Presidenta, que se autoproclama como miembro de la Juventud Maravillosa, como fue denominada la Juventud Peronista por Perón. Aquí, sí se hace referencia a una selección de sucesos de los años '70 que marcaría la diferencia en las condiciones históricas de las dos Juventudes. Los tiempos fluctúan entre el pasado y el presente del indicativo justamente porque se habla de ambas temporalidades: los años '70 y la actualidad. Esta diferencia de los tiempos gramaticales se refuerza, cuando se utilizan los mismos procesos asociados a los mismos participantes con la única diferencia de los poseedores y la polaridad (negativa o positiva):

Tabla 5: Transactividad

\begin{tabular}{|c|c|c|c|c|}
\hline Cláusula & Poseedor & Proceso Relacional & Poseído & Circunstancias \\
\hline 77 & Esa juventud & No tuvo & La oportunidad & \\
\hline 78 & (Nosotros) & Tenemos & (La oportunidad) & Hoy - Aquí \\
\hline
\end{tabular}

Tres veces se repite el sintagma "surge inevitable" y lo que se postula como inevitable no es otra cosa que la comparación entre ambas épocas. El proceso mental comparar no aparece ligado a un agente que posee la voluntad o la responsabilidad de realizar la comparación, sino que a través de un proceso relacional se lo objetiva e independiza. Es la evidencia histórica misma la que parece establecer la comparación entre las dos 
temporalidades. Por último, se vuelven a seleccionar procesos verbales (hablar) y mentales (pensar y comparar).

\subsection{Hermano}

Hoy, hoy esta maravillosa movilización no es casualidad, lo dijo el Cuervo, no, es para ustedes, yo ya fui, hermano, es para ustedes, ustedes son el futuro hermano, ustedes tienen que agarrar las banderas y llevarlas adelante (473-481)

Tabla 6: Sistema de modo

\begin{tabular}{|c|c|c|c|c|c|c|c|}
\hline & \multirow[t]{2}{*}{ Cláusula } & \multirow[t]{2}{*}{ Sujeto } & \multirow[t]{2}{*}{ Modalidad } & \multicolumn{3}{|c|}{ Elemento finito } & \multirow{2}{*}{$\begin{array}{l}\text { Adjuntos } \\
\text { modales }\end{array}$} \\
\hline & & & & $+/-$ & Tро & Modo & \\
\hline 473 & $\begin{array}{l}\text { Hoy, hoy esta maravillosa } \\
\text { movilización no es } \\
\text { casualidad, }\end{array}$ & $\begin{array}{l}\text { Esta maravillosa } \\
\text { movilización }\end{array}$ & Decl & - & Pres & Ind & \\
\hline 474 & lo dijo el Cuervo, & El Cuervo & Decl & + & Pret & Ind & \\
\hline 475 & no, & $\mathrm{X}$ & Decl & - & $\mathrm{X}$ & $\mathrm{X}$ & \\
\hline 476 & es para ustedes, & $\begin{array}{l}\text { (Esta maravillosa } \\
\text { movilización) }\end{array}$ & Decl & + & Pres & Ind & \\
\hline 477 & yo ya fui, hermano, & Yo & Decl & + & Pret & Ind & \\
\hline 478 & es para ustedes, & $\begin{array}{l}\text { (Esta maravillosa } \\
\text { movilización) }\end{array}$ & Decl & + & Pres & Ind & \\
\hline 479 & $\begin{array}{llll}\begin{array}{l}\text { ustedes son } \\
\text { hermano, }\end{array} & & \text { futuro } \\
\end{array}$ & Ustedes & Decl & + & Pres & Ind & \\
\hline 480 & $\begin{array}{l}\text { ustedes tienen que agarrar } \\
\text { las banderas }\end{array}$ & Ustedes & Decl & + & Pres & $\mathrm{X}$ & Tienen que \\
\hline 481 & y llevarlas adelante, & (Ustedes) & Decl & + & Pres & $\mathrm{X}$ & (Tienen que) \\
\hline
\end{tabular}

Según Elizabeth Rigatuso (1994), la formula de tratamiento familiar "hermano" extiende, en la actualidad, su uso a otros casos: 1) entre conocidos, como tratamiento de amistad en relaciones sociales solidarias y cercanas; 2) en negaciones enfáticas; 3 ) en saludos enfáticos; 4) en conversaciones espontaneas, se lo utiliza integrando expresiones evaluativas de conclusiones parciales; 5) en medios periodísticos radiales y televisivos, donde se escucha en boca de locutores y periodistas para sus colegas varones y 6) en el tratamiento de amabilidad y cortesía entre desconocidos, especialmente en el ámbito comercial. En todos los casos registrados, son los hombres los que utilizan este vocativo y este siempre es índice de solidaridad (RIGATUSO, 1994: 112-115). En sus estudios históricos, la autora muestra que, ya a principios del siglo XX, la formula "hermano" se extendió hacia otras relaciones familiares con especial carga afectiva y, también, como tratamiento de amistad en relaciones simétricas y cercanas (RIGATUSO, 1992: 139-140). 
Es decir que la Presidenta, haciendo uso de la jerga masculina, marca una relación amistosa, horizontal (sin diferencias etarias o de poder), de solidaridad y cercanía con el destinatario. Su utilización como intensificador se ajusta al segundo y al cuarto uso considerado por Rigatuso, aunque en este caso la supuesta espontaneidad es construida. Esto se halla en coincidencia con la utilización del apodo futbolero "Cuervo" en lugar del nombre del político, Andrés Larroque y la expresión sociolectal "yo ya fui”. En términos del tenor, se intenta producir un acercamiento basado en la igualdad de poder y la solidaridad de grupo, a través de un registro informal que comparte con sus destinatarios.

Con respecto al resto del fragmento, se reitera la oposición yo/tiempos pretéritos vs. ustedes/tiempo presente. Se cierra con modalidad deóntica, indicándoles a los jóvenes qué es lo que tienen que hacer (lo que se opone a la imagen de igualdad de poder que trasmite el vocativo).

\section{Consideraciones finales}

Cristina Fernández construye a sus destinatarios directos, la Juventud Peronista, a partir de la inclusión o la exclusión dentro de un mismo colectivo de identificación. Por un lado, forman parte del mismo grupo, en tanto cuadros del peronismo, particularmente del kirchnerismo. A su vez, del discurso se desprende algo más que iguala a la Presidenta con los jóvenes presentes en el acto: son miembros de la clase media y universitaria. En esta línea, se incluyen los vocativos "compañeros" y "hermano". Sin embargo, por otro lado, no puede dejar de hacer hincapié en las diferencias, ellos son jóvenes y pertenecen a otra generación. A esta generación la denomina "Juventud del Bicentenario" y esto le sirve para poder compararla con otra juventud cuya identidad cobró relevancia histórica, la "Juventud Maravillosa", siendo la Presidenta el puente entre ambas. Las identidades de estas dos generaciones son similares, pero la situación histórica objetiva es diferente.

Estos resultados se encuentran en concordancia con los obtenidos a partir del análisis de otros discursos de Fernández. Así, en Autor (en prensa) se muestra como la Presidenta construye diferentes nosotros que, en algunos casos, incluyen y, en otros, excluyen a la juventud militante:

1) Nosotros (Cristina Fernández - Néstor Kirchner)

2) Nosotros (Militantes años '70)

\footnotetext{
${ }^{8}$ Apodo con que se conoce a los simpatizantes del equipo de futbol San Lorenzo de Almagro 74
} 
3) Nosotros (El gobierno)

4) Nosotros (todos los presentes en el acto - todos los militantes kirchneristas)

Mientras el cuarto caso incluye a los jóvenes destinatarios dentro del mismo colectivo de identificación, para el segundo y tercer nosotros, existe un ustedes que engloba a llamada "Generación del Bicentenario". De esta forma, Cristina Fernández establece un vínculo generacional y filial con respecto a los jóvenes militantes kirchneristas. Además, establece una particular relación entre los militantes actuales y los militantes de los años '70: estos últimos deben servir de ejemplo a las nuevas generaciones. Sin embargo, la oradora coloca a la generación actual en una posición aventajada con respecto a su antecesora: tiene la posibilidad de aprender de los errores pasados, de escuchar los consejos de los mayores y de vivir en una situación histórica que se plantea como privilegiada. La idea de un contexto histórico privilegiado se reitera en otros discursos de Fernández y, también, de la agrupación La Cámpora (FLAX, 2013). En estos casos, la ventaja no reside en las capacidades de la juventud, sino en lo beneficioso de la situación política, en la valorización que el gobierno kirchnerista hace de la juventud al convocarlos a la participación política (frente a gobiernos que los persiguieron).

La comparación entre ambas generaciones de militantes, considerada en el discurso de Fernández como inevitable, le permite ubicarse en el rol de mayor dentro de una comunidad y, por lo tanto, en el rol de líder. En efecto, vimos como, en el discurso analizado en este trabajo, la legitimidad que le provee postularse como militante activa de la generación del '70 le permite generar un vínculo basado en el mandato. Sin embargo, las órdenes no resultan agresivas ni autoritarias, a pesar de que la mayoría de ellas no se encuentran mitigadas (por ejemplo, ordenes explicitas a través del imperativo y la modalidad deóntica), porque son dadas a los “chicos" (desde una posición casi maternal). Además, están mitigadas contextualmente por las alusiones a la envidia positiva y a las muchas oportunidades que poseen las nuevas generaciones. Consideramos útil volver a la definición de tenor propuesta por Martin (1992) y reformulada por White (2004) para explicar este fenómeno: las órdenes brindadas por Fernández a la juventud no atacan la imagen de esta última, en tanto se puede afirmar que, si bien existe una gran diferencia de poder entre la Presidenta y sus destinatarios, entran en juego las variables del afecto y la solidaridad valorativa e ideológica.

Recebido em: abril de 2014 Aprovado em: maio de 2015 e-mail: rocioflax@educ.ar 


\section{Referencias bibliográficas}

BROWN, P. \& LEVINSON, S. Politeness: Some Universals in Language. Cambridge: Cambridge University Press, 1987.

FAIRCLOUGH, N. Analysing Discourse. Textual Analysis for Social Research. London: Routledge, 2003.

FAIRCLOUGH, N. Critical discourse analysis. In: Revista Marges linguistiques, vol. 9, pág. 76-94. Genève: L'Institut Ferdinand de Saussure, 2005.

FLAX, R. La representación de los jóvenes en la retórica presidencial de Cristina Fernández de Kirchner. In: African Yearbook of Rethoric, vol 4.2-3, pág. 149-160. Cape Town: the Association for Rhetoric and Communication in Southern Africa. 2013.

FLAX, R. La generación del Bicentenario en el discurso de Cristina Fernández. In Perez, S. (Org.) Análisis del discurso político. Mendoza: Universidad Nacional de Cuyo, 2014, pág. 21-28.

HALLIDAY, M. El lenguaje como semiótica social. México: FCE, 1982.

Hodge, R. \& Kress, G. Language as Ideology. London: Routledge \& Kegan Paul Books, 1979.

KAPLAN, N. Nuevos desarrollos en el estudio de la evaluación en el lenguaje: la teoría de la valoración. In: Boletín de Lingüística, vol. 22, pág. 52-78. Caracas: Universidad Central de Venezuela, 2004.

LAVANDERA, B. Variación y significado. Buenos Aires: Hachette, 1984.

Lavadera, B. (1985). Decir y Aludir: una propuesta metodológica. Revista Filología, vol. 20, pág. 21-31. Buenos Aires: Universidad de Buenos Aires, 1985.

MARTIN, J. English Text. System and Structure. Amsterdam: John Benjamins, 1992.

Martin, J. \& White, P. The language of evaluation. Appraisal in English. New York: Palgrave Macmillan, 2005.

MEAD, M. Coming of age in Samoa. London: Penguin Books, 1961 [1928].

Mead, M. Cultura y Compromiso. Estudio sobre la ruptura generacional. Barcelona: Gedisa, $1997[1970]$.

POYNTON, C. Address and the Semiotics of Social Relations: a Systemic functional Account of Address Forms and Practices in Australian English. PhD Thesis. Sidney: University of Sydney, 1990.

RIGATUSO, E. Lengua, historia y sociedad. Evolución de las formular de tratamiento en el español bonaerense. Bahía Blanca: Universidad Nacional del Sur, 1992. 
RIGATUSO, E. Fórmulas de tratamiento y familia en el español bonaerense actual. Bahía Blanca: Universidad Nacional del Sur, 1994.

VAN LEEUWEN, T. Discourse and Practice. New Tools for Critical Discourse Analysis. Oxford: Oxford University Press, 2008.

WHITE, P. (2004). The Language of attitude, arguability and interpersonal positioning. [en linea] disponible en http: //www.gramatics.com/appraisal/index.html 